Boundar y- el ement cal cul at i ons for ampl i fication of effect s of I ow frequency el ectric fiel ds in a doubl et-shaped bi ol ogi cal cel I

\begin{tabular}{|l|l|}
\hline 著者 & $\begin{array}{l}\text { Seki ne Kat suhi sa, Takeda Takuya, Nagaono } \\
\text { Kaor i , Mat sushi ma Er i }\end{array}$ \\
\hline $\begin{array}{l}\text { j our nal or } \\
\text { publ i cat i on t i t l e }\end{array}$ & Bi oel ect r ochemi st ry \\
\hline vol ume & 77 \\
\hline number & 2 \\
\hline page $r$ ange & $106-113$ \\
\hline year & $2010-02-01$ \\
\hline URL & ht t p: //hdl . handl e. net /2297/19128 \\
\hline
\end{tabular}




\title{
Boundary-element calculations for amplification of effects of low-frequency electric fields in a doublet-shaped biological cell
}

\author{
Katsuhisa Sekine*, Takuya Takeda, Kaori Nagaomo and Eri Matsushima \\ Faculty of Health Sciences, Institute of Medical, Pharmaceutical and Health Sciences, Kanazawa \\ University, 5-11-80 Kodatsuno, Kanazawa, Ishikawa, 920-0942, Japan \\ sekine@kenroku.kanazawa-u.ac.jp (K. Sekine)
}

\begin{abstract}
To examine the amplification of the effects of low-frequency electric fields due to the junction between the cells, the amplitude of transmembrane potential $P_{\mathrm{TMP} 0}$, the time-averaged normal stress $\sigma_{\mathrm{n}}$ and the outward force density $\sigma_{\mathrm{out}}$ on the shell phase, and the squared intensity $I_{\mathrm{ee}}$ of electric fields in the inner and the outer phases induced by uniform external ac fields were calculated with the boundary-element method for doublet-shaped cell models consisting of two spheres of the same size connected by the junction; the results were compared with those in a spherical model. When the external fields were parallel to the long axis of the doublet-shaped models, $P_{\mathrm{TMP} 0}, \sigma_{\mathrm{n}}$ and $\sigma_{\mathrm{out}}$ at the pole were greater than those in the spherical model, and $\sigma_{\text {out }}$ and $I_{\text {ee }}$ at the junction increased with the decrease in the junction-radius. The external fields perpendicular to the long axis caused $I_{\text {ee }}$ greater than that at the center of the spherical model and negative $\sigma_{\text {out }}$ at the junction. The amplification of $P_{\mathrm{TMP} 0}, \sigma_{\mathrm{n}}, \sigma_{\mathrm{out}}$ and $I_{\mathrm{ee}}$ took place within restricted frequency-regions that could be specified by the characteristic frequencies for the frequency-dependence of the polarization factor of the models.
\end{abstract}

Keywords:

Dielectric relaxation; Electric field; Maxwell stress tensor; Simulation; Transmembrane potential

\section{K. Sekine}

Faculty of Health Sciences, Institute of Medical, Pharmaceutical and Health Sciences, Kanazawa University, 5-11-80 Kodatsuno, Kanazawa, Ishikawa, 920-0942, Japan

Tel: +81 76265 2586; fax: +81 76234 4369; sekine@kenroku.kanazawa-u.ac.jp 


\section{Introduction}

Investigations of possible health effects of non-ionizing electromagnetic fields below $300 \mathrm{GHz}$ have been carried out over 40 years [1-6]. These investigations have built the consensus that the major causes of the physiological effects of ac electric fields and those induced by ac magnetic fields are compulsory activation of voltage-sensitive channels by the induced transmembrane potential (TMP) below $100 \mathrm{kHz}$, and heating by the Joule heat above $100 \mathrm{kHz}$ [1-6]. In addition, radical pairs and magnetite crystals are considered to be the targets of magnetic fields to provide the physiological effects [4-6]. Although these effects are established from physical and chemical viewpoints, and are obvious at high field-intensities, controversy still continues about the effects of low-intensity environmental fields even with respect to reproducibility of experiments, as pointed out in the comprehensive reports [1-6], reviews [7, 8] and recent original articles $[9,10]$. This situation is attributable to lack of unified experimental protocols, and of established mechanisms to amplify the basic mechanisms to overcome inherent thermal noise [5, 6]. Amplification of TMP at the end of cell assemblies connected by the gap junction [11-14] seems to be accepted. However, other amplification mechanisms, such as the amplification of the effects of electric fields in chemical reactions within the cell membranes [15] and in neural networks [16], and that of the effects of magnetic fields in microvilli [17], are considered to need further examinations. Validity of the mechanisms of the field-effects and their amplification is expected to be evaluated from the frequency-dependence of the field-effects, as illustrated by several examples described below. Experiments by changing the field-frequency, and comparison between the experimental results and theoretical considerations provided decisive information about the mechanisms of the effects of the ac electric fields $[18,19]$. The amplification of TMP in the cell assemblies takes place at low frequencies whose high thresholds are dependent on the length of the assemblies and the impedance of the gap-junction [11-14]. In addition, many of the field-effects are reported to take place within restricted frequency-ranges, which are called "windows" with respect to frequency $[2,7,20,21]$.

From electrical viewpoints, biological cell suspensions are characterized by their inhomogeneous structure consisting of conductive cytoplasm and outer medium, and the thin insulating cell membrane surrounding the cytoplasm [22-24]. When cell models of spherical, 
spheroidal or ellipsoidal shapes placed in uniform low-frequency electric fields are used, analytical relations are available for the field-effects, such as the fields in the cells modified by the inhomogeneous structure [23, 25, 26], TMP [22, 23, 27, 28], and the Maxwell stress tensor (MST) at membrane-surfaces [29-31]. However, numerical methods are required in cases of the cells of non-ellipsoidal shapes [32-35] and non-uniform external fields [36-38].

In a previous study, we simulated the distribution of the scalar potential in budding and fission yeasts numerically under the assumption of the quasi-static condition for the ac electric fields [39]. This study indicated that the intensity of the electric field was quite amplified in the vicinity of the junction dependently on the frequency and the direction of the external fields; similar results were obtained in the cell assemblies connected by the gap junction [40]. From these results we expected that TMP and MST were also amplified dependently on the frequency and the direction of the fields in these cells. In the present study, we examined the amplification of the field-effects in doublet-shaped cell models relevant to budding yeasts in cell separation. These models consisted of two spheres of the same size connected by a junction, and were subjected to the calculations of the frequency-dependence of polarization factor (the Clausius-Mossotti factor) $\beta$ using the boundary-element method (BEM) in a previous study [41]. In the present study, BEM was extended to calculations of TMP and MST at the shell-phase. The MST was, next, modified into mechanical forces on the shell-phase, i.e. the total normal stress and the outward force density that would cause, respectively, compression and outward movement of the shell-phase. In addition, the electric fields in the inner and the outer phases in the vicinity of the junction were calculated to examine their squared intensities, because these relate to production of the Joule heat and their non-uniform distribution yields dielectrophoresis [42]. These calculations were carried out systematically by changing the direction of the external fields (parallel and perpendicular to the long axis of the models), their frequency, the radius of the junction, and the conductivity of the outer phase. The results for the field-effects were compared with the frequency-dependence of $\beta$ of the models [41] to examine whether the amplification of the field-effects could be predicted from the frequency-dependence of. $\beta$. 


\section{Methods}

\subsection{Cell model}

Fig. 1 shows the doublet-shaped cell model. This consists of two spheres $1.5 \mu \mathrm{m}$ in radius $R_{\mathrm{m}}$ representing the mother and the daughter cells centered at $\left(0,0,1.1 R_{\mathrm{m}}\right)$ and $\left(0,0,-1.1 R_{\mathrm{m}}\right)$ on $z$-axis, respectively. These spheres are connected by a junction of radius $R_{\mathrm{j}}$ represented by a ring torus. Effects of $R_{\mathrm{j}}$ were examined from the calculations for three models of different $R_{\mathrm{j}}$ : model-RDj01 $\left(R_{\mathrm{j}} / R_{\mathrm{m}}=0.1\right)$, $-\operatorname{RDj} 02\left(R_{\mathrm{j}} / R_{\mathrm{m}}=0.2\right)$, and $-\mathrm{RDj} 04\left(R_{\mathrm{j}} / R_{\mathrm{m}}=0.4\right)$. The models are surrounded by a shell-phase $7 \mathrm{~nm}$ in thickness $T$. The following values were used for the relative permittivities of the inner phase $\varepsilon_{\mathrm{i}}$, the outer phase $\varepsilon_{\mathrm{a}}$, and the shell-phase $\varepsilon_{\mathrm{s}}: \varepsilon_{\mathrm{i}}=\varepsilon_{\mathrm{a}}=80$, and $\varepsilon_{\mathrm{s}}=5.5$. The electrical conductivities of the inner phase $\kappa_{\mathrm{i}}$ and the shell-phase $\kappa_{\mathrm{s}}$ were made to be $3 \times 10^{-1} \mathrm{~S} / \mathrm{m}$ and 0 , respectively. To examine the effects of $\kappa_{\mathrm{a}}$, the calculations were carried out under the following three conditions of $\kappa_{\mathrm{a}}: \kappa_{\mathrm{a}} / \kappa_{\mathrm{i}}=10^{-3}$, $\kappa_{\mathrm{a}} / \kappa_{\mathrm{i}}=1$, and $\kappa_{\mathrm{a}} / \kappa_{\mathrm{i}}=10^{2}$. In the BEM calculations, surface of the models was discretized into 5088 isoparametric elements each of which consisted of three nodes. Linear shape functions were used in the elements. As the reference, calculations were carried out based on the analytical relations for the potential distribution for a spherical cell model [43] corresponding to a single mother cell whose center was placed at the origin of the coordinate system.

HERE FIG. 1

\subsection{BEM calculation}

Under the quasi-static conditions, spatial distributions of the scalar potential and the electric field are represented by complex quantities that contain the information about the amplitude and the phase-factor dependent on position. As did in the previous study [41], BEM calculations were carried out to solve Laplace's equation $\nabla^{2} \psi=0$ to obtain the total complex potential $\psi$ that was the sum of the external and the induced complex scalar potentials, taking account of explicit expressions for the external potential due to the external electric fields, morphology of the cell models, and the complex 
permittivities of the constituent phases defined by a relation $\varepsilon^{*}=\varepsilon+\kappa /\left(i \omega \varepsilon_{0}\right)$ with the relative permittivity $\varepsilon$, the conductivity $\kappa$, imaginary unit $i$, angular frequency $\omega$ represented as $\omega=2 \pi f$ in terms of the frequency $f$, and the permittivity of vacuum $\varepsilon_{0}$. In the present study, effects of the field-directions were examined using uniform external fields parallel to the long axis ( $z$-axis) of the models and those parallel to $x$-axis, which were, respectively, represented as $\phi_{0}=-e_{00} z$ and $\phi_{0}=-e_{00} x$, where $e_{00}$ is the field intensity.

The BEM calculations provided the values of $\psi$ and the normal components of $\nabla \psi$ in the outer phase at the surface of the shell-phase for the nodes of the discretized cell models. These quantities at other surfaces can be obtained with the following relations:

$$
\begin{aligned}
& p_{\mathrm{s}}^{\mathrm{sa}}=p_{\mathrm{a}}^{\mathrm{as}}, \\
& p_{\mathrm{s}}^{\mathrm{si}}=p_{\mathrm{i}}^{\mathrm{is}}, \\
& \varepsilon_{\mathrm{i}}^{*} q_{\mathrm{i}}^{\mathrm{is}}+\varepsilon_{\mathrm{s}}^{*} q_{\mathrm{s}}^{\mathrm{si}}=0, \\
& \varepsilon_{\mathrm{s}}^{*} q_{\mathrm{s}}^{\mathrm{sa}}+\varepsilon_{\mathrm{a}}^{*} q_{\mathrm{a}}^{\text {as }}=0 . \\
& p_{\mathrm{i}}^{\mathrm{is}}=p_{\mathrm{a}}^{\text {as }}+T\left(\varepsilon_{\mathrm{a}}^{*} / \varepsilon_{\mathrm{s}}^{*}\right) q_{\mathrm{a}}^{\mathrm{as}}, \\
& \varepsilon_{\mathrm{i}}^{*} q_{\mathrm{i}}^{\text {is }}+\varepsilon_{\mathrm{a}}^{*} q_{\mathrm{a}}^{\text {as }}=0 .
\end{aligned}
$$

In these relations, $\mathrm{i}, \mathrm{s}$, and a in subscripts and superscripts denote the inner, the shell, and the outer phases, respectively. The $p$ and $q$ shown in the form of $p_{\mathrm{A}}^{\mathrm{AB}}$ and $q_{\mathrm{A}}^{\mathrm{AB}}$ represents, respectively, $\psi$ and $\nabla \psi \cdot \mathbf{n}_{\mathrm{BEM}}^{\mathrm{AB}}$ in phase-A at the boundary between phase-A and -B, where $\mathbf{n}_{\mathrm{BEM}}^{\mathrm{AB}}$ is the unit vector 
normal to the boundary directed from phase-A to -B, A and B in subscripts and superscripts being representative of i, a, and s denoting the inner, the outer, and the shell-phases, respectively. Since $\mathbf{n}_{\mathrm{BEM}}^{\mathrm{BA}}=-\mathbf{n}_{\mathrm{BEM}}^{\mathrm{AB}}, \quad q_{\mathrm{B}}^{\mathrm{BA}}=-q_{\mathrm{A}}^{\mathrm{AB}}$. Eqs. (5) and (6) were derived under the assumption that $\nabla \psi$ in the shell-phase was independent of the depth from the surface and that $\mathbf{n}_{\mathrm{BEM}}^{\mathrm{si}}=-\mathbf{n}_{\mathrm{BEM}}^{\mathrm{sa}}$ because the thickness $T$ of the shell-phase was uniform and small.

\subsection{Calculation of TMP}

Since TMP is the difference in the potential between the inner and the outer surfaces of the shell-phase, the complex TMP, $p_{\text {TMP }}$, is derived from Eqs. (5) as

$$
p_{\mathrm{TMP}}=p_{\mathrm{i}}^{\text {is }}-p_{\mathrm{a}}^{\mathrm{as}}=T\left(\varepsilon_{\mathrm{a}}^{*} / \varepsilon_{\mathrm{s}}^{*}\right) q_{\mathrm{a}}^{\mathrm{as}} .
$$

Amplitude of TMP represented as $P_{\mathrm{TMP} 0}$ is given by $P_{\mathrm{TMP} 0}=\left(p_{\mathrm{TMP}} \overline{p_{\mathrm{TMP}}}\right)^{1 / 2}$ using $p_{\mathrm{TMP}}$ and its complex conjugate $\overline{p_{\mathrm{TMP}}}$.

\subsection{Calculation of MST}

According to the formulation for MST in inhomogeneous systems [44, 45], calculations of MST at the inner and the outer surfaces of the shell-phase require normal and tangential components of the complex electric fields at the surfaces, represented as $e_{\mathrm{n}}^{\mathrm{A} \rightarrow \mathrm{B}} \mathbf{n}_{\mathrm{MST}}^{\mathrm{A} \rightarrow \mathrm{B}}$ and $\mathbf{e}_{\mathrm{t}}^{\mathrm{A} \rightarrow \mathrm{B}}$, respectively, where A $\rightarrow \mathrm{B}$ in superscripts denotes the quantities in phase- $\mathrm{A}$ at the surface of phase- $\mathrm{B}$, and $\mathbf{n}_{\mathrm{MST}}^{\mathrm{A} \rightarrow \mathrm{B}}$ is the normal unit vector directed from phase-B to -A. These were evaluated for each element as follows:

Since the linear shape functions are used in the present study, the position vector $\mathbf{r}^{(\mathrm{ele})}$, and $p_{\mathrm{A}}^{\mathrm{AB}(\mathrm{ele})}$ and $q_{\mathrm{A}}^{\mathrm{AB}(\mathrm{ele})}$ at positions in each of the elements are represented by the following relations: 


$$
\begin{aligned}
& \mathbf{r}^{(\mathrm{ele})}(u, v)=u \mathbf{r}^{(1)}+v \mathbf{r}^{(2)}+(1-u-v) \mathbf{r}^{(\underline{3})}, \\
& p_{\mathrm{A}}^{\mathrm{AB}(\mathrm{ele})}(u, v)=u p_{\mathrm{A}}^{\mathrm{AB}(\underline{1})}+v p_{\mathrm{A}}^{\mathrm{AB}(\underline{2})}+(1-u-v) p_{\mathrm{A}}^{\mathrm{AB}(\underline{3})}, \\
& q_{\mathrm{A}}^{\mathrm{AB}(\mathrm{ele})}(u, v)=u q_{\mathrm{A}}^{\mathrm{AB}(\underline{1})}+v q_{\mathrm{A}}^{\mathrm{AB}(2)}+(1-u-v) q_{\mathrm{A}}^{\mathrm{AB}(\underline{3})},
\end{aligned}
$$

where $u$ and $v$ are variables that varies from 0 to 1 , and superscripts (1), (ㅁ) and (ㅁ) represent the parameter-values at the three apexes of the elements. The $\mathbf{r}^{(1)}, \mathbf{r}^{(2)}$ and $\mathbf{r}^{(3)}$ were decided at the stage of data preparations. Values of $p_{\mathrm{A}}^{\mathrm{AB}(\underline{1})}, p_{\mathrm{A}}^{\mathrm{AB}(2)}, p_{\mathrm{A}}^{\mathrm{AB}(\underline{3})}, q_{\mathrm{A}}^{\mathrm{AB}(\underline{1})}, q_{\mathrm{A}}^{\mathrm{AB}(\underline{2})}$ and $q_{\mathrm{A}}^{\mathrm{AB}(\underline{3})}$ were obtained from BEM calculations and Eqs. (1)-(6). Using Eqs. (8)-(10), $\mathbf{n}_{\mathrm{MST}}^{\mathrm{A} \rightarrow \mathrm{B}}, \mathbf{e}_{\mathrm{t}}^{\mathrm{A} \rightarrow \mathrm{B}}$ and $e_{\mathrm{n}}^{\mathrm{A} \rightarrow \mathrm{B}}$ were calculated for each of the elements with a method described in Appendix A.

The MST $\mathbf{T}_{n}^{\mathrm{A} \rightarrow \mathrm{B}}$ that flows from phase-A to -B through the boundary between them is represented as $\mathbf{T}_{\mathrm{n}}^{\mathrm{A} \rightarrow \mathrm{B}}=\mathbf{T}_{\mathrm{nn}}^{\mathrm{A} \rightarrow \mathrm{B}}+\mathbf{T}_{\mathrm{nt}}^{\mathrm{A} \rightarrow \mathrm{B}}$, where $\mathbf{T}_{\mathrm{nn}}^{\mathrm{A} \rightarrow \mathrm{B}}$ and $\mathbf{T}_{\mathrm{nt}}^{\mathrm{A} \rightarrow \mathrm{B}}$ are, respectively, the normal and the tangential components of the momentum contained in $\mathbf{T}_{n}^{A \rightarrow B}$. Their time-averages, $\left\langle\mathbf{T}_{n}^{A \rightarrow B}\right\rangle$, $\left\langle\mathbf{T}_{\mathrm{nn}}^{\mathrm{A} \rightarrow \mathrm{B}}\right\rangle$ and $\left\langle\mathbf{T}_{\mathrm{nt}}^{\mathrm{A} \rightarrow \mathrm{B}}\right\rangle$, are represented by the following relations:

$$
\begin{aligned}
& \left\langle\mathbf{T}_{\mathrm{n}}^{\mathrm{A} \rightarrow \mathrm{B}}\right\rangle=\left\langle\mathbf{T}_{\mathrm{nn}}^{\mathrm{A} \rightarrow \mathrm{B}}\right\rangle+\left\langle\mathbf{T}_{\mathrm{nt}}^{\mathrm{A} \rightarrow \mathrm{B}}\right\rangle, \\
& \left\langle\mathbf{T}_{\mathrm{nn}}^{\mathrm{A} \rightarrow \mathrm{B}}\right\rangle=\frac{\varepsilon_{\mathrm{A}} \varepsilon_{0}}{4}\left(e_{\mathrm{n}}^{\mathrm{A} \rightarrow \mathrm{B}} \overline{e_{\mathrm{n}}^{\mathrm{A} \rightarrow \mathrm{B}}}-\mathbf{e}_{\mathrm{t}}^{\mathrm{A} \rightarrow \mathrm{B}} \cdot \overline{\mathbf{e}_{\mathrm{t}}^{\mathrm{A} \rightarrow \mathrm{B}}} \mathbf{h}_{\mathrm{MST}}^{\mathrm{A} \rightarrow \mathrm{B}},\right. \\
& \left\langle\mathbf{T}_{\mathrm{nt}}^{\mathrm{A} \rightarrow \mathrm{B}}\right\rangle=\frac{\varepsilon_{\mathrm{A}} \varepsilon_{0}}{8}\left[\left(e_{\mathrm{n}}^{\mathrm{A} \rightarrow \mathrm{B}}+\overline{e_{\mathrm{n}}^{\mathrm{A} \rightarrow \mathrm{B}}}\right)\left(\mathbf{e}_{\mathrm{t}}^{\mathrm{A} \rightarrow \mathrm{B}}+\overline{\mathbf{e}_{\mathrm{t}}^{\mathrm{A} \rightarrow \mathrm{B}}}\right)+\left(e_{\mathrm{n}}^{\mathrm{A} \rightarrow \mathrm{B}}-\overline{e_{\mathrm{n}}^{\mathrm{A} \rightarrow \mathrm{B}}}\right)\left(\mathbf{e}_{\mathrm{t}}^{\mathrm{A} \rightarrow \mathrm{B}}-\overline{\mathbf{e}_{\mathrm{t}}^{\mathrm{A} \rightarrow \mathrm{B}}}\right)\right],
\end{aligned}
$$

where $\varepsilon_{\mathrm{A}}$ is the relative permittivity of phase- $\mathrm{A}$, and $\overline{e_{\mathrm{n}}^{\mathrm{A} \rightarrow \mathrm{B}}}$ and $\overline{\mathbf{e}_{\mathrm{t}}^{\mathrm{A} \rightarrow \mathrm{B}}}$ are the complex conjugates 
of $e_{\mathrm{n}}^{\mathrm{A} \rightarrow \mathrm{B}}$ and $\mathbf{e}_{\mathrm{t}}^{\mathrm{A} \rightarrow \mathrm{B}}$, respectively.

Since the time-averaged normal stresses at the inner and the outer surfaces of the shell-phase are $\left\langle\mathbf{T}_{\mathrm{nn}}^{\mathrm{i} \rightarrow \mathrm{s}}\right\rangle+\left\langle\mathbf{T}_{\mathrm{nn}}^{\mathrm{s} \rightarrow \mathrm{i}}\right\rangle$ and $\left\langle\mathbf{T}_{\mathrm{nn}}^{\mathrm{s} \rightarrow \mathrm{a}}\right\rangle+\left\langle\mathbf{T}_{\mathrm{nn}}^{\mathrm{a} \rightarrow \mathrm{s}}\right\rangle$, respectively, the time-averaged total normal stress $\sigma_{\mathrm{n}}$ on the shell-phase is given as

$$
\sigma_{\mathrm{n}}=\left\lfloor\left(\left\langle\mathbf{T}_{\mathrm{nn}}^{\mathrm{i} \rightarrow \mathrm{s}}\right\rangle+\left\langle\mathbf{T}_{\mathrm{nn}}^{\mathrm{s} \rightarrow \mathrm{i}}\right\rangle\right)-\left(\left\langle\mathbf{T}_{\mathrm{nn}}^{\mathrm{s} \rightarrow \mathrm{a}}\right\rangle+\left\langle\mathbf{T}_{\mathrm{nn}}^{\mathrm{a} \rightarrow \mathrm{s}}\right\rangle\right)\right] \cdot \mathbf{n}^{\mathrm{i} \rightarrow \mathrm{a}}
$$

where $\mathbf{n}^{\mathrm{i} \rightarrow \mathrm{a}}$ is the unit normal vector at the surface directed from the inner phase to the outer phase.

The shell-phase is compressed when $\sigma_{\mathrm{n}}>0$, and is expanded when $\sigma_{\mathrm{n}}<0$. Since $T$ is small, the flow of MST into the shell-phase through its cross section is negligibly smaller than those through its surfaces. Hence, the force to move the shell-phase in the direction normal to the element is approximately provided by $\left\langle\mathbf{T}_{\mathrm{nn}}^{\mathrm{a} \rightarrow \mathrm{s}}\right\rangle+\left\langle\mathbf{T}_{\mathrm{nn}}^{\mathrm{i} \rightarrow \mathrm{s}}\right\rangle$. The time-averaged force density (intensity of the force for unit area) directed outward, $\sigma_{\text {out, }}$ is represented as

$$
\sigma_{\text {out }}=\left(\left\langle\mathbf{T}_{\mathrm{nn}}^{\mathrm{a} \rightarrow \mathrm{s}}\right\rangle+\left\langle\mathbf{T}_{\mathrm{nn}}^{\mathrm{i} \rightarrow \mathrm{s}}\right\rangle\right) \cdot \mathbf{n}^{\mathrm{i} \rightarrow \mathrm{a}}
$$

\subsection{Calculation of electric field}

The BEM calculations of the electric fields can be carried out with the relations that have the same form as those for the potential and contain the gradient of the Green function, instead of the Green function $[46,47]$. In the present study, we derived the relations of this type from those for $\psi$ [48] and evaluated the complex electric fields $\mathbf{e}$ in the inner and the outer phases, using the values of $p$ and $q$ at the surfaces of the shell-phase described in section 2.2. From e and its complex conjugate $\overline{\mathbf{e}}$, we obtained the squared intensity of the induced field, $I_{\mathrm{ee}}$, given as $I_{\mathrm{ee}}=\mathbf{e} \cdot \overline{\mathbf{e}}$. 


\section{Results and discussion}

\subsection{Frequency-dependence of polarization factor}

In the previous study [41], we examined the frequency-dependence of the polarization factor $\beta$ of the doublet-shaped models. This study revealed that the frequency-dependence of the component of $\beta$ parallel to the long axis, $\beta_{z}$, was represented by a summation of three relaxation-terms, zLRD (specified by the characteristic frequency $\left.f_{\mathrm{c}}^{\mathrm{zLRD}}\right), \mathrm{zMRD}\left(f_{\mathrm{c}}^{\mathrm{zMRD}}\right)$ and $\mathrm{zHRD}\left(f_{\mathrm{c}}^{\mathrm{zHRD}}\right)$ in order of increasing frequency. On the other hand, the frequency-dependence of the component perpendicular to the long axis, $\beta_{\mathrm{h}}$, was represented with two relaxation-terms, $\operatorname{hLRD}\left(f_{\mathrm{c}}^{\mathrm{hLRD}}\right)$ and $\mathrm{hHRD}\left(f_{\mathrm{c}}^{\mathrm{hHRD}}\right)$ at lower and higher frequencies, respectively. The behavior of $\beta_{\mathrm{h}}$ was almost the same as that of the spherical models represented with LCS $\left(f_{\mathrm{c}}^{\mathrm{LCS}}\right)$ and $\operatorname{HCS}\left(f_{\mathrm{c}}^{\mathrm{HCS}}\right)$ at lower and higher frequencies, respectively, independently of directions. The increase in $\kappa_{\mathrm{a}}$ and $\kappa_{\mathrm{i}}$ caused the increase in two of the three characteristic frequencies related to $\beta_{\mathrm{z}}$, the two characteristic frequencies for $\beta_{\mathrm{h}}$, and those for the spherical models. The remaining characteristic frequency for $\beta_{z}$ was lower than that dependent on $\kappa_{\mathrm{i}}$, and decreased with the decrease in $R_{\mathrm{j}}$. Hence, under the condition that $\kappa_{\mathrm{a}} / \kappa_{\mathrm{i}}<<1, \kappa_{\mathrm{a}}$ affected $f_{\mathrm{c}}^{\mathrm{zLRD}}$, $f_{\mathrm{c}}^{\mathrm{hLRD}}$ and $f_{\mathrm{c}}^{\mathrm{LCS}}$, where $f_{\mathrm{c}}^{\mathrm{zLRD}} \approx f_{\mathrm{c}}^{\mathrm{hLRD}} \approx f_{\mathrm{c}}^{\mathrm{LCS}}, R_{\mathrm{j}} \operatorname{did} f_{\mathrm{c}}^{\mathrm{zMRD}}$, and $\kappa_{\mathrm{i}} \operatorname{did} f_{\mathrm{c}}^{\mathrm{zHRD}}, f_{\mathrm{c}}^{\mathrm{hHRD}}$ and $f_{\mathrm{c}}^{\mathrm{HCS}}$, where $f_{\mathrm{c}}^{\mathrm{zHRD}} \approx f_{\mathrm{c}}^{\mathrm{hHRD}} \approx f_{\mathrm{c}}^{\mathrm{HCS}}$. With the increase in $\kappa_{\mathrm{a}}, f_{\mathrm{c}}^{\mathrm{zLRD}}, f_{\mathrm{c}}^{\mathrm{hLRD}}$ and $f_{\mathrm{c}}^{\mathrm{LCS}}$ shifted to higher frequencies. When $\kappa_{\mathrm{a}} / \kappa_{\mathrm{i}}=1, f_{\mathrm{c}}^{\mathrm{zLRD}}<f_{\mathrm{c}}^{\mathrm{zMRD}} \approx f_{\mathrm{c}}^{\mathrm{hLRD}} \approx f_{\mathrm{c}}^{\mathrm{LCS}} \approx f_{\mathrm{c}}^{\mathrm{zHRD}} \approx f_{\mathrm{c}}^{\mathrm{hHRD}} \approx f_{\mathrm{c}}^{\mathrm{HCS}}$, where $f_{\mathrm{c}}^{\mathrm{zLRD}}$ was dependent on $R_{\mathrm{j}}$. Under the condition that $\kappa_{\mathrm{a}} / \kappa_{\mathrm{i}} \gg>1, R_{\mathrm{j}}$ affected $f_{\mathrm{c}}^{\mathrm{zLRD}}, \kappa_{\mathrm{i}}$ did $f_{\mathrm{c}}^{\mathrm{zMRD}}, f_{\mathrm{c}}^{\mathrm{hLRD}}$ and $f_{\mathrm{c}}^{\mathrm{LCS}}$, where $f_{\mathrm{c}}^{\mathrm{zMRD}} \approx f_{\mathrm{c}}^{\mathrm{hLRD}} \approx f_{\mathrm{c}}^{\mathrm{LCS}}$, and $\kappa_{\mathrm{i}} \operatorname{did} f_{\mathrm{c}}^{\mathrm{zHRD}}, f_{\mathrm{c}}^{\mathrm{hHRD}}$ and $f_{\mathrm{c}}^{\mathrm{HCS}}$, where $f_{\mathrm{c}}^{\mathrm{zHRD}} \approx f_{\mathrm{c}}^{\mathrm{hHRD}} \approx f_{\mathrm{c}}^{\mathrm{HCS}}$.

In the present study, the field-effects were calculated at various positions in the cell models as the function of the frequency under the various conditions of the field-direction, $\kappa_{\mathrm{a}}$ and $R_{\mathrm{j}}$. The three $\kappa_{\mathrm{a}} / \kappa_{\mathrm{i}}$-values used in the present study, $\kappa_{\mathrm{a}} / \kappa_{\mathrm{i}}=10^{-3}, \kappa_{\mathrm{a}} / \kappa_{\mathrm{i}}=1$ and $\kappa_{\mathrm{a}} / \kappa_{\mathrm{i}}=10^{2}$, correspond to the 
conditions $\kappa_{\mathrm{a}} / \kappa_{\mathrm{i}}<<1, \kappa_{\mathrm{a}} / \kappa_{\mathrm{i}}=1$ and $\kappa_{\mathrm{a}} / \kappa_{\mathrm{i}}>>1$, respectively. The $R_{\mathrm{j}}$ was changed to examine whether $R_{\mathrm{j}}$ would cause the same effects on frequency-dependence of the field-effects as those on $\beta$. Preliminary calculations showed that marked amplification of $P_{\mathrm{TMP} 0}, \sigma_{\mathrm{n}}$, and $\sigma_{\mathrm{out}}$ was found at the following positions in the shell phase: at the pole $\left(0,0,2.1 R_{\mathrm{m}}\right)$, and in the middle of junction on $x$-axis $\left(R_{\mathrm{j}}, 0,0\right)$ and that on $y$-axis $\left(0, R_{\mathrm{j}}, 0\right)$. Amplification of $I_{\mathrm{ee}}$ in the vicinity of the junction was examined in the inner-phase at the center of the junction $(0,0,0)$, and in the outer-phase beside the junction on $x$-axis at $\left(0.45 R_{\mathrm{m}}, 0,0\right)$ and on $y$-axis at $\left(0,0.45 R_{\mathrm{m}}, 0\right)$. When the external fields were parallel to $z$-axis, amplitudes of the field-effects were independent of the direction in $x y$-plane due to the axially symmetric shape of the models.

\subsection{Field-effects induced by external field parallel to z-axis under the condition $\kappa_{a} / \kappa_{i}=10^{-3}$}

This section describes the field-effects under the conditions that the external field was parallel to $z$-axis and $\kappa_{\mathrm{a}} / \kappa_{\mathrm{i}}=10^{-3}$, because all of the field-effects were amplified under this condition.

The $P_{\mathrm{TMP} 0}$ and $\sigma_{\mathrm{n}}$ at the pole were almost independent of $R_{\mathrm{j}}$; frequency-dependence of these parameters in model-RDj01 are shown in Fig. 2, which also shows $P_{\mathrm{TMP0}}$ and $\sigma_{\mathrm{n}}$ at the pole of the single spherical model represented by solid lines as the reference. In the frequency-region below $f_{\mathrm{c}}^{\mathrm{zLRD}}, P_{\mathrm{TMP} 0}$ in the doublet-shaped models was about twice (1.8 times) as large as that in the spherical model (Fig. 2(A)). The ratio of $\sigma_{\mathrm{n}}$ below $f_{\mathrm{c}}^{\mathrm{zLRD}}$ for the doublet-shaped model to that for the spherical model was about 3.0 (Fig. 2(B)), which was larger than the ratio in $P_{\text {TMP0}}$.

\section{HERE FIG. 2}

Fig. 3(A) shows the frequency-dependence of $\sigma_{\text {out }}$ at the pole of the doublet-shaped models and that for the single spherical model. Fig. 3(B) shows the frequency-dependence of $\sigma_{\text {out }}$ at the junction side, together with $\sigma_{\text {out }}$ at the equator of the spherical model as the reference. At the pole shown in Fig. $3(\mathrm{~A}), \sigma_{\text {out }}$ in the doublet-shaped model was about twice (2.1 times) as large as that in the spherical 
model in the frequency-region between $f_{\mathrm{c}}^{\mathrm{zLRD}}$ and $f_{\mathrm{c}}^{\mathrm{zMRD}}$. At the junction side in Fig. 3(B), increase in $\sigma_{\text {out }}$ took place between $f_{\mathrm{c}}^{\mathrm{zMRD}}$ and $f_{\mathrm{c}}^{\mathrm{zHRD}}$, and the maximum of $\sigma_{\text {out }}$ increased with the decrease in $R_{\mathrm{j}}$. When $R_{\mathrm{j}}$ was small, the maximum of $\sigma_{\mathrm{out}}$ at the junction side exceeded that at the pole. HERE FIG. 3

Fig. 4(A) shows the frequency-dependence of $I_{\mathrm{ee}}$ at the junction-center, and that at the center of the spherical model. Fig. 4(B) compares $I_{\mathrm{ee}}$ outside of the junction $\left(0.45 R_{\mathrm{m}}, 0,0\right)$ for the doublet-shaped models and that for the spherical model at an equivalent position $\left(0.45 R_{\mathrm{m}}, 0,-1.1 R_{\mathrm{m}}\right)$. At both inside and outside of the junction, $I_{\mathrm{ee}}$ increased with the decrease in $R_{\mathrm{j}}$ in the frequency-region between $f_{\mathrm{c}}^{\mathrm{zMRD}}$ and $f_{\mathrm{c}}^{\text {zHRD }}$.

\section{HERE FIG. 4}

Fig. 5 shows the dependence of $I_{\mathrm{ee}}$ on $z$ along $z$-axis in the inner phase at the frequencies where values of $I_{\mathrm{ee}}$ reach the maximum in each of the models: 3, 5.4, and $10 \mathrm{MHz}$ for model-RDj01, -RDj02 and $-\mathrm{RDj} 04$, respectively. This figure shows that $I_{\mathrm{ee}}$ increases locally nearby the junction. Similar results were obtained in the calculations of $I_{\mathrm{ee}}$ in the outer phase at various positions in $x y$-plane (data not shown).

HERE FIG. 5

\subsection{Conditions for amplification of field-effects}

The results of the calculations described in the preceding section, under the condition that the external fields were parallel to the long-axis $\left(z\right.$-axis) and $\kappa_{\mathrm{a}} / \kappa_{\mathrm{i}}=10^{-3}$, showed that the field-effects were amplified dependently on the position and the frequency. The frequency-regions in which the effects were amplified were specified by the characteristic frequencies for $\beta_{\mathrm{z}}$. In addition, the results suggest that the effects of $R_{\mathrm{j}}$ on the amplified intensities are classified into two groups: the one in which the intensities are independent of $R_{\mathrm{j}}$ as shown in Figs. 2(A), 2(B) and 3(A) or reached to a 
constant value independent of $R_{\mathrm{j}}$, and the other in which the intensities increase with the decrease in $R_{\mathrm{j}}$ as shown in Figs. 3(B), 4(A) and 4(B). The same situation applied to the amplification of the field-effects under the other conditions of $\kappa_{\mathrm{a}}\left(\kappa_{\mathrm{a}} / \kappa_{\mathrm{i}}=1\right.$ and $\left.\kappa_{\mathrm{a}} / \kappa_{\mathrm{i}}=10^{2}\right)$ and the field-direction (parallel to $x$-axis) examined in the present study, as described below.

The amplification did not take place at frequencies higher than $f_{\mathrm{c}}^{\mathrm{zHRD}}$ and $f_{\mathrm{c}}^{\mathrm{hHRD}}$ $\left(f_{\mathrm{c}}^{\mathrm{zHRD}} \approx f_{\mathrm{c}}^{\mathrm{hHRD}}\right)$ irrespective of the $\kappa_{\mathrm{a}}$-values and the field-directions. In this frequency-region, the shell-phase is considered to be short-circuited due to its capacitive component, and to cause no detectable effects arising from its deformed shape. Hence, if physiological field-effects on the cells in separation are observed in this frequency-region, these are attributable to specific interactions between molecules and the fields.

The $P_{\mathrm{TMP} 0}$ and $\sigma_{\mathrm{n}}$ were amplified only at the pole under the external fields parallel to the long axis (z-axis) at frequencies below $f_{\mathrm{c}}^{\mathrm{zLRD}}$ irrespective of the change in $\kappa_{\mathrm{a}}$. The result with respect to $P_{\text {TMP0 }}$ is consistent with the simulations for the cell-assemblies connected by the gap-junctions, and is attributable to elongated shape of the models along the direction of the external field [11-14]. The high threshold $f_{\mathrm{c}}^{\mathrm{zLRD}}$ of the frequency-region is dependent on $R_{\mathrm{j}}$ when $\kappa_{\mathrm{a}} / \kappa_{\mathrm{i}} \geq 1$, however, is dependent on $\kappa_{\mathrm{a}}$ when $\kappa_{\mathrm{a}} / \kappa_{\mathrm{i}}<<1$. Under this condition, the shell-phase at the pole is subjected to amplified electrical $\left(P_{\mathrm{TMP} 0}\right)$ and mechanical $\left(\sigma_{\mathrm{n}}\right)$ turbulence that is expected to affect the function of membrane proteins. Amplified $\sigma_{\text {out }}$ at the pole $\left(\sigma_{\text {out }}[\mathrm{z}, \mathrm{P}]\right)$ was caused under the condition in which the fields were parallel to $z$-axis, $\kappa_{\mathrm{a}} / \kappa_{\mathrm{i}}<<1$ and the frequencies were between $f_{\mathrm{c}}^{\mathrm{zLRD}}$ and $f_{\mathrm{c}}^{\mathrm{zMRD}}$. Since $\sigma_{\text {out }}[\mathrm{z}, \mathrm{P}]$ was positive, the fields promote elongation of the doublet-shaped cells under this condition.

The $\sigma_{\text {out }}$ at the junction-side $\left(\sigma_{\text {out }}[\mathrm{z}, \mathrm{JS}]\right)$ and $I_{\mathrm{ee}}$ at the junction-center $\left(I_{\mathrm{ee}}[\mathrm{z}, \mathrm{JC}]\right)$ due to the fields parallel to $z$-axis had the same properties; these were amplified within a frequency-region whose low and high thresholds were dependent on $R_{\mathrm{j}}$ and $\kappa_{\mathrm{i}}$, respectively, i.e. between $f_{\mathrm{c}}^{\mathrm{zMRD}}$ and $f_{\mathrm{c}}^{\mathrm{zHRD}}$ when $\kappa_{\mathrm{a}} / \kappa_{\mathrm{i}}<<1$, and between $f_{\mathrm{c}}^{\mathrm{zLRD}}$ and $f_{\mathrm{c}}^{\mathrm{zMRD}}$ when $\kappa_{\mathrm{a}} / \kappa_{\mathrm{i}} \geq 1$. The $\sigma_{\text {out }}[\mathrm{z}, \mathrm{JS}]$ was positive, and both $\sigma_{\text {out }}[\mathrm{z}, \mathrm{JS}]$ and $I_{\mathrm{ee}}[\mathrm{z}, \mathrm{JC}]$ increased with the decrease in $R_{\mathrm{j}}$. The positive $\sigma_{\text {out }}[\mathrm{z}, \mathrm{JS}]$ operates to 
increase $R_{\mathrm{j}}$ oppositely to the decrease in $R_{\mathrm{j}}$ accompanied by the cell division. The amplified $I_{\mathrm{ee}}[\mathrm{z}, \mathrm{JC}]$ causes the amplified production of the Joule heat and the dielectrophoresis due to the gradient of $I_{\mathrm{ee}}$ in the inner-phase near the junction. These field-effects are expected to affect the cell division, because they are amplified with the progress of the cell division.

The $\sigma_{\text {out }}$ at the junction-side and $I_{\mathrm{ee}}$ at the junction-center were amplified also under the fields parallel to $x$-axis. The $\sigma_{\text {out }}[\mathrm{x}, \mathrm{JSy}]$ caused by these fields at $\left(0, R_{\mathrm{j}}, 0\right)$ was negative and its absolute value increased with the decrease in $R_{\mathrm{j}}$ at frequencies lower than the characteristic frequencies dependent on $\kappa_{\mathrm{a}}$, i.e. below $f_{\mathrm{c}}^{\mathrm{hLRD}}$ when $\kappa_{\mathrm{a}} / \kappa_{\mathrm{i}}<<1$, and below $f_{\mathrm{c}}^{\mathrm{hHRD}}$ when $\kappa_{\mathrm{a}} / \kappa_{\mathrm{i}} \geq 1\left(f_{\mathrm{c}}^{\mathrm{hLRD}} \approx\right.$ $f_{\mathrm{c}}^{\mathrm{zLRD}}$ and $\left.f_{\mathrm{c}}^{\mathrm{hHRD}} \approx f_{\mathrm{c}}^{\mathrm{zHRD}}\right)$. The negative $\sigma_{\mathrm{out}}[\mathrm{x}, \mathrm{JSy}]$ competes against the positive $\sigma_{\text {out }}[\mathrm{z}, \mathrm{JS}]$ in the frequency-region between $f_{\mathrm{c}}^{\mathrm{zLRD}}$ and $f_{\mathrm{c}}^{\mathrm{zMRD}}$ when $\kappa_{\mathrm{a}} / \kappa_{\mathrm{i}} \geq 1$. However, under other conditions of the frequency and the conductivity, it operates alone to compress the junction in the direction perpendicular to the field-direction. Under the condition that $\kappa_{\mathrm{a}} / \kappa_{\mathrm{i}} \geq 1$, the fields parallel to $x$-axis caused amplified $\sigma_{\text {out }}[\mathrm{x}, \mathrm{JSx}]$ at $\left(R_{\mathrm{j}}, 0,0\right)$ and $I_{\mathrm{ee}}[\mathrm{x}, \mathrm{JC}]$ at the junction-center at frequencies between $f_{\mathrm{c}}^{\mathrm{hLRD}}$ and $f_{\mathrm{c}}^{\mathrm{hHRD}}$. The $\sigma_{\text {out }}[\mathrm{x}, \mathrm{JSx}]$ was negative and its absolute value was about three times as large as that at $\left(R_{\mathrm{m}}, 0,0\right)$ in the spherical model subjected to the same external fields. The $I_{\mathrm{ee}}[\mathrm{x}, \mathrm{JC}]$ was about three times as large as that at the center of the spherical model.

The $I_{\mathrm{ee}}$ in the outer medium beside the junction $\left(I_{\mathrm{ee}}[\mathrm{z}, \mathrm{JO}]\right)$ was amplified only under the fields parallel to $z$-axis at frequencies between $f_{\mathrm{c}}^{\mathrm{zMRD}}$ and $f_{\mathrm{c}}^{\mathrm{zHRD}}$ when $\kappa_{\mathrm{a}} / \kappa_{\mathrm{i}}<<1$. It increased with the decrease in $R_{\mathrm{j}}$. The Joule heat produced by this amplified $I_{\mathrm{ee}}$ in the outer medium is considered to be much lower than that in the inner phase at the junction-center, because the production of the Joule heat in the unit volume and time is a product of $I_{\mathrm{ee}}$ and the conductivity, where $\kappa_{\mathrm{a}}$ is much smaller than $\kappa_{\mathrm{i}}$. Hence, the chief effect of the amplified $I_{\mathrm{ee}}$ beside the junction is considered to be the dielectrophoresis due to the non-uniformity of $I_{\mathrm{ee}}$ caused by the locally amplified $I_{\mathrm{ee}}$ close to the junction.

\subsection{Proposed experimental procedure to examine the significance of amplified field-effects}


Physiological effects of electromagnetic fields on biological cells can be detected rather simply by measuring the cell division rate $[18,49]$ and/or the induction of the heat-shock proteins [50]. The present study has shown that the field-effects are amplified within specific frequency-regions divided by the characteristic frequencies for the polarization factors. This suggests that the significance of the amplified field-effects can be examined from the experiments in which the frequencies of the external ac fields are changed, as adopted in the previous studies by Glasser and Fuhr [18], and Matsuoka [19]. The experimental frequency-range is required to be wide enough so that it includes the characteristic frequencies for the polarization factor. Since the characteristic frequencies and the frequency-range in which the field-effects are amplified are dependent of the conductivity $\kappa_{\mathrm{a}}$ of the outer medium, additional experiments by changing $\kappa_{\mathrm{a}}$ are expected to provide further information, if these are experimentally practicable. The field-direction can be fixed when the specimens are cultured in agar plates $[51,52]$. Use of temperature-sensitive mutants is expected to enable us to start the cell cycle at a required time by changing the temperature $[49,53,54]$, and to detect the physiological changes in the cells with high sensitivity [55].

\section{Conclusion}

The theoretical calculations in present study showed that the amplitude of transmembrane potential $P_{\mathrm{TMP} 0}$, the time-averaged normal stress $\sigma_{\mathrm{n}}$ and the outward force density $\sigma_{\mathrm{out}}$ on the shell phase, and the squared intensity $I_{\mathrm{ee}}$ of electric fields in the inner and the outer phases induced by uniform ac fields were amplified in the doublet shaped cell models, dependently on the direction and the frequency of the fields, and the conductivity $\kappa_{\mathrm{a}}$ of the outer medium. Some of the field-effects were intensified with the decrease in the radius $R_{\mathrm{j}}$ of the junction. These effects are expected to affect the processes of the cell division accompanied by the decrease in $R_{\mathrm{j}}$. The frequency-specific nature of the amplified field-effects was consistent with the "windows" with respect to frequency in the physiological effects of the fields. The frequency-regions where the field-effects were amplified were specified by the characteristic frequencies that characterize the frequency-dependence of the 
polarization factor of the cell models. Hence, if the characteristic frequencies are obtained from separate experiments or theoretical calculations in advance, the significance of the amplified field-effects can be examined from the experiments in which the frequency is changed over the frequency-region that extends from the characteristic frequency toward low and high frequencies.

\section{Symbols in the text}

Letters A and B in subscripts and superscripts are representative of $i$, a, and s denoting the inner, the outer, and the shell phases, respectively. Letters in boldface represent vectors or tensors.

$e_{00} \quad$ intensity of external electric field

e complex electric field

e complex conjugate of $\mathbf{e}$

$e_{\mathrm{n}}^{\mathrm{A} \rightarrow \mathrm{B}} \quad$ complex intensity of normal component of electric field in phase-A from phase-B to $-\mathrm{A}$

$\overline{e_{\mathrm{n}}^{\mathrm{A} \rightarrow \mathrm{B}}} \quad$ complex conjugate of $e_{\mathrm{n}}^{\mathrm{A} \rightarrow \mathrm{B}}$

$\mathbf{e}_{\mathrm{t}}^{\mathrm{A} \rightarrow \mathrm{B}} \quad$ complex tangential component of electric field in phase-A at the surface of phase-B

$\overline{\mathbf{e}_{t}^{A \rightarrow B}} \quad$ complex conjugate of $\mathbf{e}_{t}^{A \rightarrow B}$

$f \quad$ frequency of external electric field

$f_{\mathrm{c}}^{\mathrm{LCS}}$ and $f_{\mathrm{c}}^{\mathrm{HCS}}$

characteristic frequencies of LCS and HCS

$f_{\mathrm{c}}^{\mathrm{hLRD}}$ and $f_{\mathrm{c}}^{\mathrm{hHRD}}$

characteristic frequencies of hLRD and hHRD

$f_{\mathrm{c}}^{\mathrm{zLRD}}, f_{\mathrm{c}}^{\mathrm{zMRD}}$ and $f_{\mathrm{c}}^{\mathrm{zHRD}}$

characteristic frequencies of zLRD, zMRD and zHRD

hLRD and hHRD

relaxation terms at low and high frequencies for doublet-shaped model perpendicular to long axis 
imaginary unit

$I_{\mathrm{ee}}$ squared intensity of the induced field; $I_{\mathrm{ee}}=\mathbf{e} \cdot \overline{\mathbf{e}}$

$I_{\mathrm{ee}}[\mathrm{x}, \mathrm{JC}] \quad I_{\mathrm{ee}}$ at the junction-center due to ac fields parallel to $x$-axis

$I_{\mathrm{ee}}[\mathrm{z}, \mathrm{JC}] \quad I_{\mathrm{ee}}$ at the junction-center due to ac fields parallel to $z$-axis

$I_{\mathrm{ee}}[\mathrm{z}, \mathrm{JO}] \quad I_{\mathrm{ee}}$ beside the junction due to ac fields parallel to $z$-axis

\section{LCS and HCS}

relaxation terms at low and high frequencies for spherical model

$\mathbf{n}_{\mathrm{BEM}}^{\mathrm{AB}} \quad$ unit normal vector directed from phase-A to -B

$\mathbf{n}_{\mathrm{MST}}^{\mathrm{A} \rightarrow \mathrm{B}} \quad$ unit normal vector directed from phase-B to -A

$\mathbf{n}^{\mathrm{i} \rightarrow \mathrm{a}} \quad$ normal unit vector at surface of models directed from inner to outer phase

$p_{\mathrm{A}}^{\mathrm{AB}} \quad$ total complex potential in phase-A at boundary between phase- $\mathrm{A}$ and $-\mathrm{B}$

$p_{\mathrm{A}}^{\mathrm{AB}(\mathrm{ele})} \quad p_{\mathrm{A}}^{\mathrm{AB}}$ in elements

$p_{\mathrm{A}}^{\mathrm{AB}(\underline{1})}, p_{\mathrm{A}}^{\mathrm{AB}(\underline{2})}$ and $p_{\mathrm{A}}^{\mathrm{AB}(\underline{3})}$

$p_{\mathrm{A}}^{\mathrm{AB}}$ at apexes of each element

$p_{\text {TMP }}$

complex transmembrane potential

$p_{\mathrm{TMP}} \quad$ complex conjugate of $p_{\mathrm{TMP}}$

$P_{\text {TMP0 }} \quad$ amplitude of TMP

$P_{\mathrm{TMPO}}[\mathrm{z}, \mathrm{P}] \quad P_{\mathrm{TMP0}}$ at the pole due to ac fields parallel to $z$-axis

$q_{\mathrm{A}}^{\mathrm{AB}} \quad \nabla \psi \cdot \mathbf{n}_{\mathrm{BEM}}^{\mathrm{AB}}$ in phase-A at boundary between phase-A and -B

$q_{\mathrm{A}}^{\mathrm{AB}(\mathrm{ele})} \quad q_{\mathrm{A}}^{\mathrm{AB}}$ in elements

$q_{\mathrm{A}}^{\mathrm{AB}(1)}, q_{\mathrm{A}}^{\mathrm{AB}(2)}$ and $q_{\mathrm{A}}^{\mathrm{AB}(3)}$

$q_{\mathrm{A}}^{\mathrm{AB}}$ at apexes of each element

$\mathbf{r}^{(\mathrm{ele})} \quad$ position vector directed to elements

$\mathbf{r}^{(1)}, \mathbf{r}^{(2)}$ and $\mathbf{r}^{(3)}$

position vectors directed to apexes of each element 


$$
\begin{array}{ll}
R_{\mathrm{j}} & \text { radius of junction } \\
R_{\mathrm{m}} & \text { radius of mother and daughter cells } \\
T & \text { thickness of shell phase } \\
\mathbf{T}_{\mathrm{n}}^{\mathrm{A} \rightarrow \mathrm{B}} & \text { Maxwell stress tensor (MST) from phase-A to -B } \\
\mathbf{T}_{\mathrm{nn}}^{\mathrm{A} \rightarrow \mathrm{B}} \text { and } \mathbf{T}_{\mathrm{nt}}^{\mathrm{A} \rightarrow \mathrm{B}}
\end{array}
$$

normal and tangential components of the momentum contained in $\mathbf{T}_{\mathrm{n}}^{\mathrm{A} \rightarrow \mathrm{B}}$

$$
\left\langle\mathbf{T}_{\mathrm{n}}^{\mathrm{A} \rightarrow \mathrm{B}}\right\rangle,\left\langle\mathbf{T}_{\mathrm{nn}}^{\mathrm{A} \rightarrow \mathrm{B}}\right\rangle \text {, and }\left\langle\mathbf{T}_{\mathrm{nt}}^{\mathrm{A} \rightarrow \mathrm{B}}\right\rangle
$$

time averages of $\mathbf{T}_{\mathrm{n}}^{\mathrm{A} \rightarrow \mathrm{B}}, \mathbf{T}_{\mathrm{nn}}^{\mathrm{A} \rightarrow \mathrm{B}}$, and $\mathbf{T}_{\mathrm{nt}}^{\mathrm{A} \rightarrow \mathrm{B}}$

$u$ and $v \quad$ variables in the linear shape function

zLRD, zMRD and zHRD

relaxation terms at low, medium and high frequencies for doublet-shaped model parallel to long axis

$$
\text { polarization factor of cell model }
$$

$\beta_{\mathrm{z}}$ and $\beta_{\mathrm{h}} \quad$ components of $\beta$ parallel and perpendicular to long axis of doublet-shaped cell model

$$
\text { permittivity of vacuum }
$$

$\varepsilon_{\mathrm{i}}, \varepsilon_{\mathrm{a}}$, and $\varepsilon_{\mathrm{s}}$ relative permittivities of inner, outer, and shell phases

$\varepsilon_{\mathrm{i}}^{*}, \varepsilon_{\mathrm{a}}^{*}$, and $\varepsilon_{\mathrm{s}}^{*}$

$$
\text { complex permittivities of inner, outer, and shell phases }
$$

$$
\phi_{0} \quad \text { complex external potential }
$$

$\kappa_{\mathrm{i}}, \kappa_{\mathrm{a}}$, and $\kappa_{\mathrm{s}}$ conductivities of inner, outer, and shell phases

$\sigma_{\mathrm{n}} \quad$ time-averaged total normal stress on shell phase

$\sigma_{\mathrm{n}}[\mathrm{z}, \mathrm{P}] \quad \sigma_{\mathrm{n}}$ at the pole due to ac fields parallel to $z$-axis

$\sigma_{\text {out }} \quad$ time-averaged outward force density on shell phase

$\sigma_{\text {out }}[\mathrm{x}, \mathrm{JSx}] \quad \sigma_{\text {out }}$ at $\left(R_{\mathrm{j}}, 0,0\right)$ due to ac fields parallel to $x$-axis

$\sigma_{\text {out }}[\mathrm{x}, \mathrm{JSy}] \quad \sigma_{\text {out }}$ at $\left(0, R_{\mathrm{j}}, 0\right)$ due to ac fields parallel to $x$-axis

$\sigma_{\text {out }}[\mathrm{z}, \mathrm{JS}] \quad \sigma_{\text {out }}$ at the junction-side due to ac fields parallel to $z$-axis 
$\sigma_{\text {out }}[\mathrm{z}, \mathrm{P}] \quad \sigma_{\text {out }}$ at the pole due to ac fields parallel to $z$-axis

$\omega$ angular frequency of external electric field; $\omega=2 \pi f$

$\psi$ total complex potential

\section{Acknowledgement}

Authors appreciate Dr. K. Asami, Kyoto University, for critical reading of the manuscript.

\section{Appendix A.}

From Eq. (8) in the text, a unit vector $\mathbf{n}^{(\mathrm{ele})}$ normal to the element is represented by the following relation:

$$
\mathbf{n}^{(\mathrm{ele})}=\left(\mathbf{r}_{u}^{(\mathrm{ele})} \times \mathbf{r}_{v}^{(\mathrm{ele})}\right) /\left|\mathbf{r}_{u}^{(\mathrm{ele})} \times \mathbf{r}_{v}^{(\mathrm{ele})}\right|,
$$

where

$$
\begin{aligned}
& \mathbf{r}_{u}^{(\mathrm{ele})}=\partial \mathbf{r}^{(\mathrm{ele})} / \partial u=\mathbf{r}^{(1)}-\mathbf{r}^{(\underline{3})} \\
& \mathbf{r}_{v}^{(\mathrm{ele})}=\partial \mathbf{r}^{(\mathrm{ele})} / \partial v=\mathbf{r}^{(\underline{2})}-\mathbf{r}^{(3)}
\end{aligned}
$$

The $\mathbf{n}_{\mathrm{MST}}^{\mathrm{A} \rightarrow \mathrm{B}}$ for the element, $\mathbf{n}_{\mathrm{MST}}^{\mathrm{A} \rightarrow \mathrm{B}(\mathrm{ele})}$, was obtained from $\mathbf{n}^{(\mathrm{ele})}$ with a relation $\mathbf{n}_{\mathrm{MST}}^{\mathrm{A} \rightarrow \mathrm{B}(\mathrm{ele})}= \pm \mathbf{n}^{(\mathrm{ele})}$. Since the direction of $\mathbf{n}^{(\text {ele })}$ is dependent on the assignment of the index to the nodes decided at the stage of data preparations, the sign attached to $\mathbf{n}^{(\text {ele })}$ was chosen manually so that the direction $\mathbf{n}_{\mathrm{MST}}^{\mathrm{A} \rightarrow \mathrm{B}(\mathrm{ele})}$ might be suitable.

The $\mathbf{e}_{t}^{A \rightarrow B}$ for the element, $\mathbf{e}_{t}^{A \rightarrow B(e l e)}$, is required to satisfy the following relations: 


$$
\begin{aligned}
& -\left(\mathbf{e}_{\mathrm{t}}^{\mathrm{A} \rightarrow \mathrm{B}(\text { ele })} \cdot \mathbf{r}_{u}^{(\text {ele })}\right) \mathrm{d} u=p_{\mathrm{A}}^{\mathrm{AB}(\text { ele })}(u+\mathrm{d} u, v)-p_{\mathrm{A}}^{\mathrm{AB}(\mathrm{ele})}(u, v), \\
& -\left(\mathbf{e}_{\mathrm{t}}^{\mathrm{A} \rightarrow \mathrm{B}(\text { ele })} \cdot \mathbf{r}_{v}^{(\text {ele })}\right) \mathrm{d} v=p_{\mathrm{A}}^{\mathrm{AB}(\text { ele })}(u, v+\mathrm{d} v)-p_{\mathrm{A}}^{\mathrm{AB}(\text { ele })}(u, v),
\end{aligned}
$$

where $\mathbf{r}_{u}^{(\text {ele) }}$ and $\mathbf{r}_{v}^{(\text {ele) }}$ are given by Eqs. (A2) and (A3), respectively, and $p_{\mathrm{A}}^{\mathrm{AB}(\text { ele) }}$ is represented as Eq. (9) in the text as the function of $u$ and $v$. Hence, $\mathbf{e}_{t}^{\mathrm{A} \rightarrow \mathrm{B}(\mathrm{ele})}$ is represented as.

$$
\mathbf{e}_{\mathrm{t}}^{\mathrm{A} \rightarrow \mathrm{B}(\mathrm{ele})}=\mathbf{e}_{\mathrm{tu}}^{\mathrm{A} \rightarrow \mathrm{B}(\mathrm{ele})}+\mathbf{e}_{\mathrm{tv}}^{\mathrm{A} \rightarrow \mathrm{B}(\mathrm{ele})}
$$

where

$$
\begin{aligned}
\mathbf{e}_{\mathrm{tu}}^{\mathrm{A} \rightarrow \mathrm{B}(\mathrm{ele})} & =-\frac{\left(\partial p_{\mathrm{A}}^{\mathrm{AB}(\mathrm{ele})} / \partial v\right) r_{u v}^{(\mathrm{ele})}-\left(\partial p_{\mathrm{A}}^{\mathrm{AB}(\mathrm{ele})} / \partial u\right) r_{v v}^{(\mathrm{ele})}}{\left(r_{u v}^{(\mathrm{ele})}\right)^{2}-r_{u u}^{(\mathrm{ele})} r_{v v}^{(\mathrm{ele})}} \mathbf{r}_{u}^{(\mathrm{ele})} \\
& =-\frac{\left(p_{\mathrm{A}}^{\mathrm{AB}(\underline{2})}-p_{\mathrm{A}}^{\mathrm{AB}(\underline{3})}\right) r_{u v}^{(\mathrm{ele})}-\left(p_{\mathrm{A}}^{\mathrm{AB}(1)}-p_{\mathrm{A}}^{\mathrm{AB}(\underline{3})}\right) r_{v v}^{(\mathrm{ele})}}{\left(r_{u v}^{(\mathrm{ele})}\right)^{2}-r_{u u}^{(\mathrm{ele})} r_{v v}^{(\mathrm{ele})}} \mathbf{r}_{u}^{(\mathrm{ele})},
\end{aligned}
$$

$$
\begin{aligned}
\mathbf{e}_{\mathrm{tv}}^{\mathrm{A} \rightarrow \mathrm{B}(\mathrm{ele})} & =-\frac{\left(\partial p_{\mathrm{A}}^{\mathrm{AB}(\mathrm{ele})} / \partial u\right) r_{u v}^{(\mathrm{ele})}-\left(\partial p_{\mathrm{A}}^{\mathrm{AB}(\mathrm{ele})} / \partial v\right) r_{u u}^{(\mathrm{ele})}}{\left(r_{u v}^{(\mathrm{ele})}\right)^{2}-r_{u u}^{(\mathrm{ele})} r_{v v}^{(\mathrm{ele})}} \mathbf{r}_{v}^{(\mathrm{ele})} \\
& =-\frac{\left(p_{\mathrm{A}}^{\mathrm{AB}(1)}-p_{\mathrm{A}}^{\mathrm{AB}(\underline{3})}\right) r_{u v}^{(\mathrm{ele})}-\left(p_{\mathrm{A}}^{\mathrm{AB}(2)}-p_{\mathrm{A}}^{\mathrm{AB}(\underline{3})}\right) r_{u u}^{(\mathrm{ele})}}{\left(r_{u v}^{(\mathrm{ele})}\right)^{2}-r_{u u}^{(\mathrm{ele})} r_{v v}^{(\mathrm{ele})}} \mathbf{r}_{v}^{(\mathrm{ele})},
\end{aligned}
$$

$$
r_{u v}^{(\mathrm{ele})}=\mathbf{r}_{u}^{(\mathrm{ele})} \cdot \mathbf{r}_{v}^{(\mathrm{ele})}
$$

$$
r_{u u}^{(\mathrm{ele})}=\mathbf{r}_{u}^{(\mathrm{ele})} \cdot \mathbf{r}_{u}^{(\mathrm{ele})}
$$




$$
r_{v v}^{(\mathrm{ele})}=\mathbf{r}_{v}^{(\mathrm{ele})} \cdot \mathbf{r}_{v}^{(\mathrm{ele})}
$$

The $e_{\mathrm{n}}^{\mathrm{A} \rightarrow \mathrm{B}}$ for the element, $e_{\mathrm{n}}^{\mathrm{A} \rightarrow \mathrm{B}(\mathrm{ele})}$, was obtained from $q_{\mathrm{A}}^{\mathrm{AB}(\mathrm{ele})}$ at the mass-center of the element. From Eq. (10) in the text, this is given as $\left(q_{\mathrm{A}}^{\mathrm{AB}(1)}+q_{\mathrm{A}}^{\mathrm{AB}(2)}+q_{\mathrm{A}}^{\mathrm{AB}(\underline{3})}\right) / 3$. Since $\mathbf{n}_{\mathrm{MST}}^{\mathrm{A} \rightarrow \mathrm{B}(\text { ele })}=-\mathbf{n}_{\mathrm{BEM}}^{\mathrm{AB}(\text { ele })}, e_{\mathrm{n}}^{\mathrm{A} \rightarrow \mathrm{B}(\text { ele })}$ is represented as

$$
e_{\mathrm{n}}^{\mathrm{A} \rightarrow \mathrm{B}(\mathrm{ele})}=\left(q_{\mathrm{A}}^{\mathrm{AB}(\underline{1})}+q_{\mathrm{A}}^{\mathrm{AB}(2)}+q_{\mathrm{A}}^{\mathrm{AB}(\underline{3})}\right) / 3 .
$$




\section{References}

[1] American National Standards Institute, American National Standard Techniques and Instrumentation for the Measurement of Potentially Hazardous Electromagnetic Radiation at Microwave Frequencies (ANSI C95.3-1973), The Institute of Electrical and Electronics Engineers, New York, 1973.

[2] National Radiological Protection Board, Review of the scientific evidence for limiting exposure to electromagnetic fields (0-300 GHz), Doc. NRPB (2004), Vol. 15, No. 3

[3] IEEE International Committee on Electromagnetic Safety, IEEE Standard for Safety Levels with Respect to Human Exposure to Radio Frequency Electromagnetic Fields, $3 \mathrm{kHz}$ to $300 \mathrm{GHz}$ (IEEE Std C95.1-2005), The Institute of Electrical and Electronics Engineers, New York, 2005.

[4] World Health Organization, 2006 WHO Research Agenda for Radio Frequency Fields, World Health Organization, Geneva, 2007.

[5] World Health Organization, Extremely Low Frequency Fields (Environmental Health Criteria 238) World Health Organization, Geneva, 2007.

[6] World Health Organization, 2007 WHO Research Agenda for Extremely Low Frequency Fields, World Health Organization, Geneva, 2007.

[7] H. Berg, Problems of weak electromagnetic field effects in cell biology, Bioelectrochem. Bioenerg., 48, (1999) 355 - 360

[8] J.C. McKay, F.S. Prato, A.W. Thomas, A literature review: The effects of magnetic field exposure on blood flow and blood vessels in the microvasculature, Bioelectromagnetics, 28 , (2007) $81-98$

[9] M.J.R Gómez, M.I.P. Barcia, E.R. Bogajo, M.M. Morillo, Static and $50 \mathrm{~Hz}$ magnetic fields of 0.35 and $2.45 \mathrm{mT}$ have no effect on the growth of Saccharomyces cerevisiae, Bioelectrochem., 64 , (2004) $151-155$

[10] M.J.R Gómez, M.D.M. Moyano, M.G.C. Martin, M.I.P. Barcia, M.M. Morillo, No effect of 50 $\mathrm{Hz} 2.45 \mathrm{mT}$ magnetic field on the potency of cisplatin, mitomycin C, and methotrexate in $S$. cerevisiae, Electromagnetic Biol. Med., 27, (2008) 289 - 297

[11] A.A. Pilla, P.R. Nasser, J.J. Kaufman, Gap junction impedance, tissue dielectrics and thermal 
noise limits for electromagnetic field bioeffects, Bioelectrochem. Bioenerg., 35, (1994) 63 - 69

[12] E.C. Fear, M.A. Stuchly, Biological cells with gap junctions in low-frequency electric fields, IEEE Trans. Biomed. Engin., 45, (1998) 856 - 866

[13] E.C. Fear, M.A. Stuchly, Modeling assemblies of biological cells exposed to electric fields, IEEE Trans. Biomed. Engin., 45, (1998) 1259 - 1271

[14] E.C. Fear, M.A. Stuchly, A novel equivalent circuit model for gap-connected cells, Phys. Med. Biol., 43, (1998) 1439 - 1448

[15] E. Neumann, Digression on chemical electromagnetic field effects in membrane signal transduction - Cooperativity paradigm of the acetylcholine receptor, Bioelectrochem. Bioenerg., $52,(2000) 43-49$

[16] R.K. Adair, Simple neural networks for the amplification and utilization of small changes in neuron firing rates, Proc. Natl. Acad. Sci. USA, 98, (2001) 7253 - 7258

[17] J. Gartzke, K. Lange, Cellular target of weak magnetic fields: Ionic conduction along actin filaments of microvilli, Am. J. Physiol. Cell Physiol., 283, (2002) 1333 - 1346

[18] H. Glasser, G. Fuhr, Cultivation of cells under strong ac-electric field - Differentiation between heating and trans-membrane potential effects, Bioelectrochem. Bioenerg., 47, (1998) 301 - 310

[19] H. Matsuoka, K. Hashimoto, S. Horikiri, M. Saito, K. Yamamoto, J. Ando, Single-cell imaging of the $\mathrm{Ca}^{2+}$ influx into bovine endothelial cells occurring in response to an alternating electric stimulus, Anal. Sci., 18, (2002) 1205 - 1208

[20] E. Postow, M.L. Swichord, Modulated fields and "window" effects, in: C. Polk, E. Postow (Eds.), Handbook of Biological Effects of Electromagnetic Fields, 2nd ed., CRC Press, Boca Raton, New York, London, Tokyo, 1996, pp. 535-580

[21] V.N. Binhi, R.J. Goldman, Ion-protein dissociation predicts 'windows' in electric field-induced wound-cell proliferation, Biochim. Biophys. Acta, 1474, (2000) 147 - 156

[22] U. Zimmermann, The effect of high intensity electric field pulses on eukaryotic cell membranes: Fundamentals and applications, in: U. Zimmermann, G.A. Neil (Eds.), Electromanipulation of Cells, CRC Press, Boca Raton, 1996, pp. 1-106

[23] K.R. Foster, H.P. Schwan, Dielectric properties of tissues, in: C. Polk, E. Postow (Eds.), 
Handbook of Biological Effects of Electromagnetic Fields, 2nd ed., CRC Press, Boca Raton, New York, London, Tokyo, 1996, pp. 25-102

[24] K. Asami, Dielectric relaxation spectroscopy of biological cell suspensions, in: V.A. Hackley, J. Texter (Eds.), Handbook on Ultrasonic and Dielectric Characterization Techniques for Suspended Particulates, The Americal Ceramic Society, Westerville, 1998, pp. 333-349

[25] D. Wachner, M. Simeonova, J. Gimsa, Estimating the subcellular absorption of electric field energy: Equations for an ellipsoidal single shell model, Bioelectrochem., 56, (2002) 211 - 213

[26] M. Simeonova, D. Wachner, J. Gimsa, Cellular absorption of electric field energy: Influence of molecular properties of the cytoplasm, Bioelectrochem., 56, (2002) 215 - 218

[27] T. Kotnik, D. Miklavčič, Analytical description of transmembrane voltage induced by electric fields on spheroidal cells, Biophys. J., 79, (2000) 670 - 679

[28] K. Maswiwat, D. Wachner, J. Gimsa, Effects of cell orientation and electric field frequency on the transmembrane potential induced in ellipsoidal cells, Bioelectrochem., 74, (2008) 130 - 141

[29] M. Winterhalter, W. Helfrich, Deformation of spherical vesicles by external fields, J. Coll. Interface Sci., 122, (1988) 583 - 586

[30] M. Kummrow, W. Helfrich, Deformation of giant lipid vesicles by electric fields, Phys. Rev. A, 44, (1991) $8356-8360$

[31] M.D. Mitov, P. Meleard, M. Winterhalter, P. Bothorel, Electric-field dependent thermal fluctuation of giant vesicles, Phys. Rev. E, 48, (1993) 628 - 631

[32] C. Liu, D. Sheen, K. Huang, A hybrid numerical method to compute erythrocyte TMP in low-frequency electric fields, IEEE Trans. Nanobiosci., 2, (2003) 104 - 109

[33] S. Muñoz San Martín, J.L. Sebastián, M. Sancho, J.M. Miranda, A study of the electric field distribution in erythrocyte and rod shape cells from direct RF exposure, Phys. Med. Biol., 48, (2003) $1649-1659$

[34] J.L. Sebastián, S. Muñoz San Martín, M. Sancho, J.M. Miranda, Modelling the internal field distribution in human erythrocytes exposed to MW radiation, Bioelectrochem., 64, (2004) 39 - 45

[35] J.L. Sebastián, S. Muñoz, M. Sancho, J.M. Miranda, Analysis of the electric field induced forces in erythrocyte membrane pores using a realistic cell model, Phys. Med. Biol., 51, (2006) 6213 - 
[36] M. Pavlin, N. Pavšelj, D. Miklavčič, Dependence of induced transmembrane potential on cell density, arrangement, and cell position inside a cell system, IEEE Trans. Biomed. Eng., 49, (2002) $605-612$

[37] T.R. Gowrishankar, D.A. Stewart, J.C. Weaver, Model of a confined spherical cell in uniform and heterogeneous applied electric fields, Bioelectrochem., 68, (2006) 181 - 190

[38] A.M. Benselama, P. Pham, P. Atten, P., Calcul de la force diélectrophorétique dans les microsystèmes biologiques: comparaison du modèle dipolaire avec le modèle du tenseur de Maxwell, J. Electrostatics, 64, (2006) 437 - 444

[39] K. Asami, K. Sekine, Dielectric modelling of cell division for budding and fission yeast, J. Phys. D: Appl. Phys., 40, (2007) 1128 - 1133

[40] K. Asami, Dielectric properties of biological tissues in which cells are connected by communicating junctions, J. Phys. D: Appl. Phys., 40, (2007) 3718 - 3727

[41] K. Sekine, Y. Watanabe, S. Hara, K. Asami, Boundary-element calculations for dielectric behavior of doublet-shaped cells, Biochim. Biophys. Acta, 1721, (2005) 130 - 138

[42] T.B. Jones, Electromechanics of Particles, Cambridge University Press, Cambridge, New York, Melbourne, 1995, 29 p.

[43] H. Pauly, H.P. Schwan, Über die Impedanz einer Suspension von kugelfförmigen Teilchen mit einer Schale, Z. Naturforsch., 14b, (1959) 125 - 131

[44] F.A. Sauer, Interaction forces between microscopic particles in an external electromagnetic field, in: A. Chiabrera, C. Nicolini, H.P. Schwan (Eds.), Interactions between Electromagnetic Fields and Cells, Plenum, New York, 1985, pp. 181-202

[45] F.A. Sauer, R. W. Schlögl, Torques exerted on cylinders and spheres by external electromagnetic fields: A contribution to the theory of field induced rotation, in: A. Chiabrera, C. Nicolini, H.P. Schwan (Eds.), Interactions between Electromagnetic Fields and Cells, Plenum, New York, 1985, pp. $203-251$

[46] Y.B. Yildir, K.M. Prasad, D. Zhen, Computer-aided design in electromagnetic systems: Boundayr element method and applications, in: C.T. Leondes (Ed.), Control and Dynamic Systems, vol. 59, 
Academic Press, San Diego, Tokyo, 1993, pp. 167-223

[47] C. Zimmermann, M. Stern, Boundary element solution of 3-D wave scatter problems in a proelastic medium, Eng. Anal. Boundary Elements, 12, (1993) 223 - 240

[48] K. Sekine, Application of boundary element method to calculation of the complex permittivity of suspensions of cells in shape of $\mathrm{D}_{\infty \mathrm{h}}$ symmetry, Bioelectrochem., 52, (2000) 1 - 7

[49] H. Matsuoka, S. Matsumoto, M. Kinoshita, S. Yamada, Effective stage in the cell cycle for control of the budding direction of cdc mutants of Saccharomyces cerevisiae using electric stimulus, Biochim. Biophys. Acta, 971, (1988) 255 - 265

[50] M. Blank, R. Goodman, A mechanism for stimulation of biosynthesis by electromagnetic fields: Charge transfer in DNA and base pair separation, J. Cell. Physiol., 214, (2008) 20 - 26

[51] M. Zhao, A.A-. Fernandez, J.V. Forrester, C.D. McCaig, Orientation and directed migration of cultured corneal epithelial cells in small electric fields are serum dependent, J. Cell Sci., 109, (1996) $1405-1414$

[52] M. Zhao, J.V. Forrester, C.D. Mccaig, A small, physiological electric field orients cell division, Proc. Natl. Acad. Sci. USA, 96, (1999) 4942 - 4946

[53] K. Asami, E. Gheorghiu, T. Yonezawa, Dielectric behavior of budding yeast in cell separation, Biochim. Biophys. Acta, 1381, (1998) 234 - 240

[54] K. Asami, E. Gheorghiu, T. Yonezawa, Real-Time Monitoring of Yeast Cell Division by Dielectric Spectroscopy, Biophys. J., 76, (1999) 3345 - 3348

[55] R.G. Guven, K. Guven, A. Dawe, J. Worthington, C. Harvell, A. Popple, T. Smith, B. Smith, D.I. de Pomerai, Effects of radio-frequency fields on bacterial cell membranes and nematode temperature-sensitive mutants, Enzyme Microb Technol., 39, (2006) 788 - 795 


\section{Figure Captions}

Fig. 1.

Doublet-shaped cell model used in the present study. The cell interior is covered by the shell-phase of uniform thickness $T$ represented by a bold solid line.

Fig. 2.

Frequency-dependence of (A) the amplitude of the transmembrane potential $P_{\mathrm{TMP} 0}$ and (B) the time-averaged normal stress $\sigma_{\mathrm{n}}$ normalized by the field-intensity $e_{00}$ at the pole $\left(0,0,2.1 R_{\mathrm{m}}\right)$ of model-RDj01 ( $\circ$ ) under the condition that the external fields are parallel to the long axis of the models $\left(z\right.$-axis) and $\kappa_{\mathrm{a}} / \kappa_{\mathrm{i}}=10^{-3}$. Solid lines in (A) and (B) represent $P_{\mathrm{TMP} 0}$ and $\sigma_{\mathrm{n}}$ at the pole of the spherical cell model. Vertical lines zLRD, zMRD1 and zHRD represent the characteristic frequencies for the polarization factor of model-RDj01 along $z$-axis.

Fig. 3 .

Frequency-dependence of the time-averaged outward force densities $\sigma_{\text {out }}(\mathrm{A})$ at the pole and (B) at the junction side $\left(R_{\mathrm{j}}, 0,0\right)$ normalized by $e_{00}$ for model-RDj01 (०), -RDj02 (•) and $-\operatorname{RDj} 04(\square)$, under the condition that the external fields are parallel to $z$-axis and $\kappa_{\mathrm{a}} / \kappa_{\mathrm{i}}=10^{-3}$. Solid lines in (A) and (B) represent $\sigma_{\text {out }}$ at the pole and the equator of the spherical cell model. Vertical lines zMRD1, zMRD2 and zMRD4 represent the characteristic frequency of the relaxation term zMRD for model-RDj01, -RDj02 and -RDj04, respectively.

Fig. 4.

Frequency-dependence of the squared intensity of the induced field $I_{\mathrm{ee}}(\mathrm{A})$ inside $(0,0,0)$ and (B) outside $\left(0.45 R_{\mathrm{m}}, 0,0\right)$ of the junction normalized by $e_{00}$ for model-RDj01 (०), -RDj02 (•) and -RDj04 ( $\square$ ), under the condition that the external fields are parallel to $z$-axis and $\kappa_{\mathrm{a}} / \kappa_{\mathrm{i}}=10^{-3}$. Solid lines in (A) and (B) represent $I_{\mathrm{ee}}$ at the center and at an equivalent position in the outer phase for the spherical cell 
model.

Fig. 5.

Dependence of $I_{\mathrm{ee}}$ on $z$ along $z$-axis in the inner phase for model-RDj01at $3 \mathrm{MHz}(\mathrm{O}),-\operatorname{RDj} 02$ at 5.4

$\mathrm{MHz}(\bullet)$ and $-\mathrm{RDj} 04$ at $10 \mathrm{MHz}(\square)$, under the conditions that the external fields are parallel to $z$-axis and $\kappa_{\mathrm{a}} / \kappa_{\mathrm{i}}=10^{-3}$. 


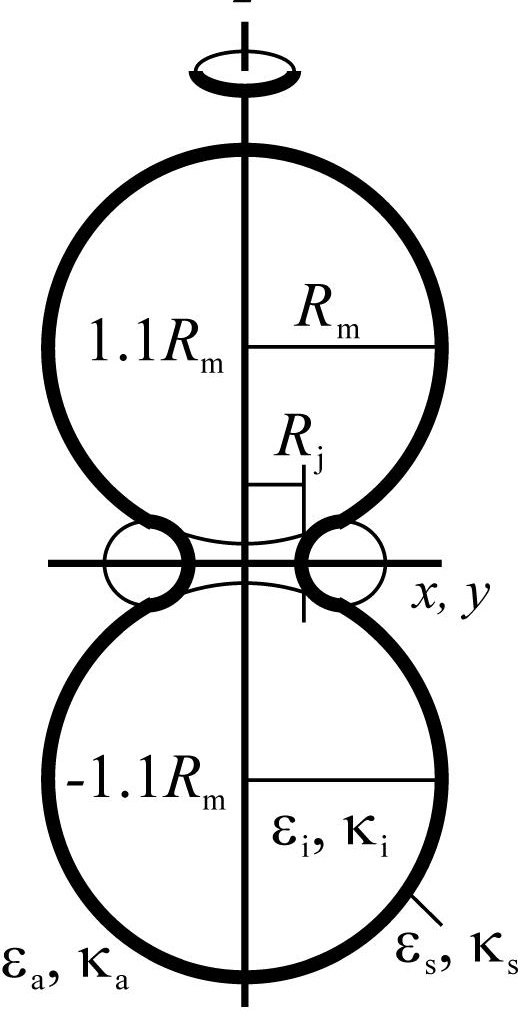

Fig.1 K.Sekine 


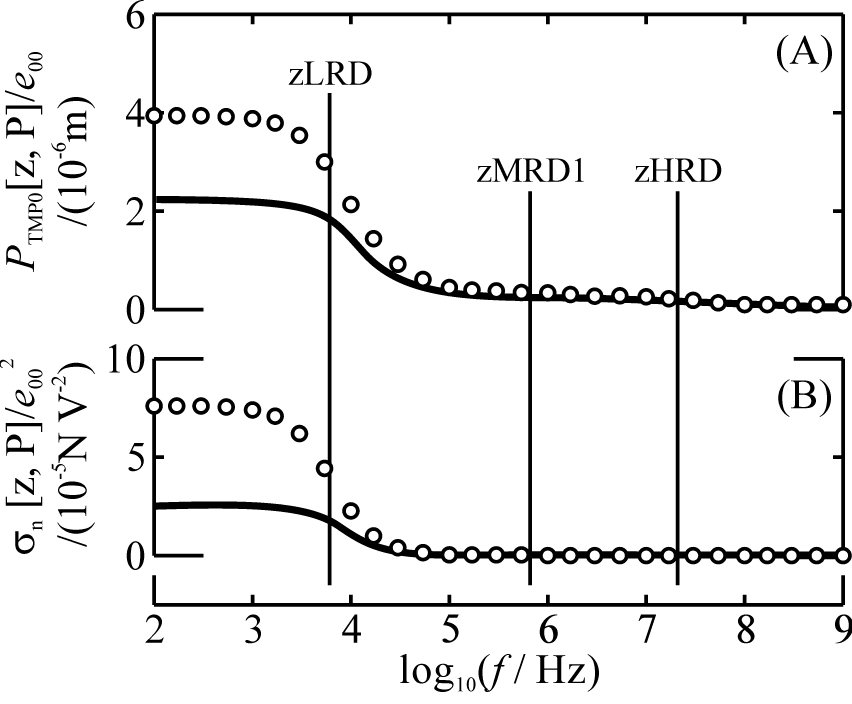

Fig. 2 K.Sekine 
v 
20<smiles>c1ccccc1</smiles>

$\underbrace{2}_{0}$

$10-0$

— 880806

a

a

0.0

0.5

1.0

$z / R_{\mathrm{m}}$

Fig.5 K.Sekine 